\author{
辻田星 歩*1, 右 田 和 也*2

\section{Investigation for Secondary Flow and Loss Generation Mechanisms within Centrifugal Impeller by Using Rotating Curved Duct (2nd Report, Influence of Inlet Pitchwise Velocity Distribution)}

\author{
Hoshio TSUJITA*3 and Kazuya MIGITA \\ *3 Department of Mechanical Engineering, Hosei University, \\ 3-7-2 Kajino-cho, Koganei-shi, Tokyo, 184-8584 Japan
}

\begin{abstract}
The passage vortex in a centrifugal impeller is generated by the centrifugal force caused by the curvature of impeller passage and the Coriolis force induced by the rotation, and strongly affects the loss generation in the impeller channel. Therefore, the control of passage vortex results in the reduction of loss generation. In the present study, the flow within the rotating curved duct which is considered to be a simplified model for centrifugal impeller channels was analyzed numerically in order to reveal the effects of the inlet pitchwise velacity distribution on the formation of passage vortex. The computed results revealed that the thicker boundary layer on the suction side wall than that on the pressure side at the inlet of the bend suppresses the development of passage vortex and consequently reduces the associated loss generation. Moreover, the results were examined in detail by relating with the flow in a centrifugal impeller.
\end{abstract}

Key Words: Turbomachinery, Secondary Flow, Computational Fluid Dynamics, Loss Generation, Passage Vortex

\section{1. 粕 言}

遠心羽根車はポンプ，ターボチャージャおよびガス タービンなどのターボ形の流体機械の主要な構成要素 として多用されている(1).その回転する羽根車流路内 の相対流れには子午面内の流路の曲率による遠心力に 加えて，回転によるコリオリ力が作用することにより 非常に複雑な二次流れが誘起される. その二次流れは 損失生成の増大を引き起こすだけでなく，壁面付近の 境界層内の高損失流体の移動および集積に奇与するた め, 羽根車出口でのウェークの強さおよびその位置に 影響を与える. その結果羽根車性能を左右する主要パ ラメータである羽根車出口流出角に影響を与える. し たがって，遠心羽根車の性能向上には二次流れの制御 が不可欠である.

回転する遠心羽根車内の二次流九は流路渦, 馬蹄形

* 原稿受付 2009 年 9 月 24 日.

*1. 正員, 法政大学理工学部 (- 184-8584 小金井市梶野町 3-72).

*2 学生員, 法政大学大学院工学研究科.

E-mail : tsujita@hosei.ac.jp
渦や漏れ渦等の複数の渦により構成されている. その 中で最も支配的なものは流路渦であり，その流路渦生 成の基本モデルとして回転曲がりダクトが考えられる. 本研究では, 回転曲がりダクトのベンド形状を遠心羽 根車の子午面形状と関連付け(図 1), 羽根車流路内の流 れに影響を与える流体力学的パラメータを考慮して回 転曲がりダクト内の流れを解析寸ることにより，遠心 羽根車流路内の二次流れの形成およびそれによる損失
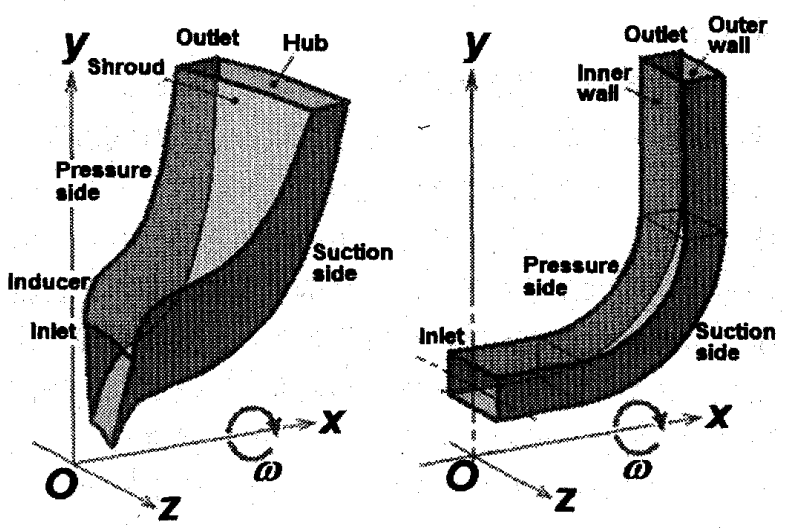

Fig.1 Centrifugal impeller and rotating curved duct 
生成機構を解明することを目的としている. また，圧

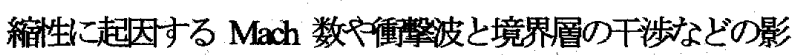
響を除外するために，実機こ比べると比較的低い Reynolds 数の流九を対象としている. 直交性の良い計算格子の生 成が可能な曲がりダクト内の流れの解析結果は，高い 信頼性を有すると考えられる.

第 1 報(2)では回転曲がりダクト内の基本的な二次流 れが，遠心圧縮機羽根車内の二次流れ采と一致してい ることを示した. さらに「ベンドの曲率による遠心力」 と「回転によるコリオリ力」の比を表す Rossby 数が, 回転曲がりダクト内の流路渦の形成および損失生成に 与える影響について明らかにした. 遠心羽根車の入口 速度分布は入射角により変化し, 羽根車流路内の二次 流れの形成に影響を与える. 本報ではこの速度分布の 変化を模擬した入口境界条件を与えて, 回転曲がりダ クト内の流れの数值解析を行うことにより，その変化 が二次流れの形成および損失生成へ与える影響につい て調べた.

\section{2.おもな歫号}

$A_{c p s}$ ：負荷保数

$C_{p s} \quad: p$ に基づく静圧係数

$C_{p s}^{*}: p^{*}$ に基づく静圧係数

$C_{p t}: p_{t}$ に基づく全圧損失倸数

$C_{p t}^{*}: p_{t}^{*}$ に基づく全圧損失倸数

$N$ : 回転数 [rpm]

$p$ : 静圧 [Pa]

$p^{*}$ : 回転による圧力上昇を除いた静圧 $[\mathrm{Pa}]$

$p_{t}$ : 全圧 $[\mathrm{Pa}]$

$p_{t}^{*}$ ：回転による圧力上昇を除いた全圧 $[\mathrm{Pa}]$

$Q \quad:$ 体積流量 $\left[\mathrm{m}^{3} / \mathrm{s}\right]$

$R_{c}:$ 平均曲率半径 $=0.5\left(r_{i}+r_{o}\right) \quad[\mathrm{m}]$

$R_{e} \quad$ : Reynolds 数

$R_{o} \quad$ : Rossby 数

$R_{r} \quad:$ 半径比 $=R_{c} / D$

$R_{n} \quad$ : ダクト入口での回転半径 $[\mathrm{m}]$

$r^{*} \quad:$ 管高さ方向無次元座標 $=\left(r_{o}-r\right) / H$

$V_{c}$ : 断面平均流速 $[\mathrm{m} / \mathrm{s}]$

$X_{s} \quad$ : ダクト流路方向無次元座標

$\Delta C_{p t}: \mathrm{CE}$ に誘起された流路渦に起因する全压 損失倸数

$\Delta C_{p}^{*}:$ : CO の付加による流路渦の増強に起因す る全圧損失係数

$\beta$ : ベンド出口での流れ角 [deg.]

$\delta_{V}:$ 入口速度分布パラメータ

$\rho$ : 密度 $\left[\mathrm{kg} / \mathrm{m}^{3}\right]$ $\theta \quad:$ ベンド内流路方向座標 [deg.]

$\omega_{i a b s}: V_{c}$ て無次元化された相対二次流れ速度成 分に基づく渦度の流路方向成分の絶対值 $\left.\mathbf{m}^{-1}\right]$

添 字 : 角速度 $[\mathrm{rad} / \mathrm{s}]$

,i : 断面質量平均値

,ij : ダクト高さ(k)方向質量平均值

,ik : ダクト幅(j)方向質量平均値

\section{3. 数值解析法}

本数值解析法では，回転座標系上の相対流れに対寸 る物理成分テンソル形の定常非圧縮性乱流の基礎方程 式を，有限体積法により離散化した ${ }^{(4)(5)}$. 乱流モデルに は標準の $k$-\&モデルを壁法則と共に用いた. 対流項は三 次風上差分法により評価した ${ }^{(6)}$. 計算のアルゴリズム は SIMPLE 法であり, 収束判定条件は全解析領域での 質量残差の総和が入口質量流量の $0.01 \%$ 以下になった 場合とした. 本解析法による計算精度は文献(5)(7)等で 検証されている.

\section{4. 曲がりダクトの形状および折条件}

図 1 および図 2 に解析対象の曲がりダクトの形状を 示す. 断面形状は正方形で水力直径 $D=0.04 \mathrm{~m}$, 曲がり 角 $\alpha=90^{\circ}$, 平均曲率半径 $R_{c}=0.092 \mathrm{~m}$ であり, 半径比 $R_{r}=2.3$ である. 回転軸から入口側直管中心までの距離 で定義される回転半径 $R_{r c}=1.5 \mathrm{D}$ とした. 図 1 に示す ように, 本研究では遠心羽根車の子午面内の流路の湾 曲を曲がりダクトのベンド部によりモデル化している. 遠心羽根車のインデューサ部の湾曲については幾何学 的にはモデル化されていないが，その湾曲に起因する遠心 力の二次流れへの影響梳小さいもと考える ${ }^{(8)}$.

図 3 に遠心羽根車入口における翼間面内の相対 流れの入射角とピッチ方向速度分布の関係を示す.

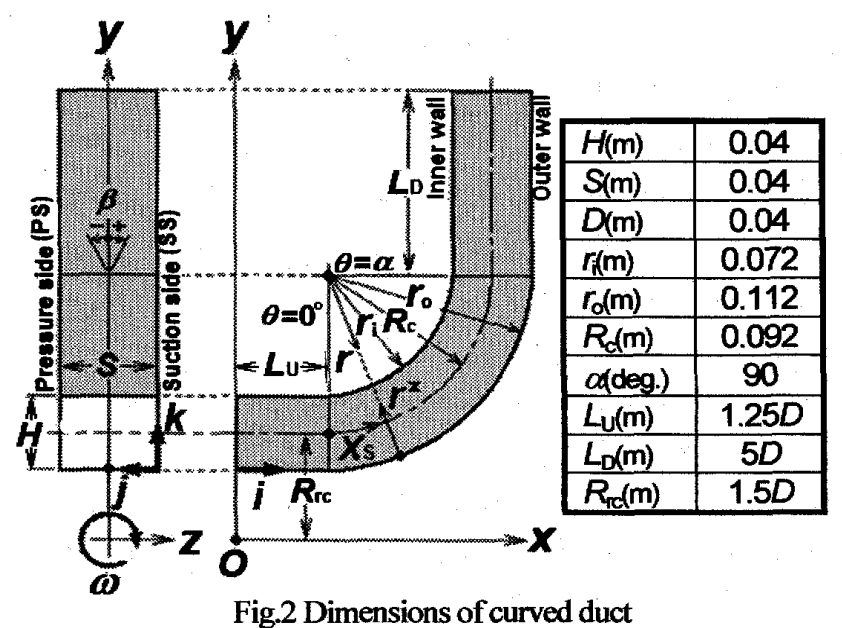




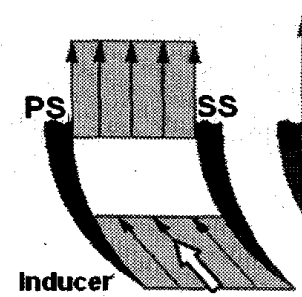

(a) Zero incidence

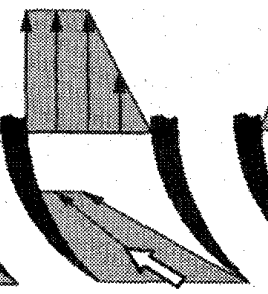

(b) Positive incidence

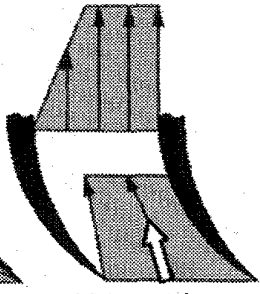

(c) Negative incidence

Fig. 3 Velocity distribution on blade-to-blade surface of centrifugal impeller

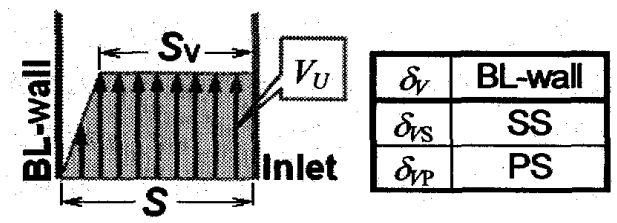

Fig.4 Parameter for inlet velocity distribution

インデューサへの入射角がゼロの場合はほぼ一様 速度分布を形成するが, 正の入射角に対しては負 圧面側で，逆に負の入射角に対しては圧力面側で それぞれ境界層が発達する．以上のように入射角 により変化する羽根車入口ピッチ方向速度分布が, 翼間流路内の二次流れおよび損失生成に与える影 響を調べるために，本研究では式(1)で定義される 入口速度分布パラメータ $\delta_{V}$ により規定される相対 速度分布を，回転曲がりダクトの入口境界条件と して管幅(j)方向に与え，その内部流れの数值解析 を行った.

$$
\delta_{V}=\frac{S-S_{V}}{S}
$$

$\delta_{V}$ は速度勾配域を境界層と見なした場合, 管幅 $S$ に対 する境界層厚さ $S-S_{V}$ の割合を表している (図 4). $\delta_{V}$ は回転曲がりダクトの場合は，速度勾配を付けた側 の側壁(BL-wall)に応じて，負圧面側(SS)の場合を $\delta_{V S}$, 压力面側(PS)の場合を $\delta_{V P}$ として示す。また, 本研究では静止曲がりダクトを対象とした解析も 実施しているが，その場合恃負圧面と圧力面の区 別はないため $\delta_{V}$ と示す. 入口の管高さ $(\mathbf{k})$ 方向の速 度分布については一様に与えた. 出口境界条件とし ては連続の条件を満足するように主流方向速度を決定 した:

本研究においては表 1 に示す異なる三つの回転数 $N$ に対して，表 2 に示す入口速度勾配 $\delta_{V}$ をSS 側壁と PS 側壁のどちらか一方に与えて解析を行った.すべての 解析条件において流量が固定されるように，一様流領 域の速度 $V_{U}$ と速度勾配 $\delta_{V}$ を調節して分布を決定した

Table 1 Calculation conditions

\begin{tabular}{|c|c|c|c|c|}
\hline$N(\mathrm{~mm})$ & $V_{c}(\mathrm{~m} / \mathrm{s})$ & $Q\left(\mathrm{~m}^{3} / \mathrm{s}\right)$ & $R_{e}$ & $R_{0}$ \\
\hline 50 & & & & 2.08 \\
\hline 100 & \multirow{2}{*}{1.0} & $1.63 \times 10^{-3}$ & 40,000 & 1.04 \\
\cline { 1 - 2 } & & & & 0.69 \\
\hline 150 & & & &
\end{tabular}

Table 2 Values of $\delta_{V}$

\begin{tabular}{|l|l|l|l|l|l|l|}
\hline \multicolumn{7}{|c|}{$\delta_{Y}\left(\delta_{V S,} \delta_{V P}\right)$} \\
\hline 0.0 & 0.05 & 0.1 & 0.15 & 0.2 & 0.25 & 0.3 \\
\hline
\end{tabular}

(図 4). したがって，本解析条件の設定が意図している 遠心羽根車への入射角の変化は，一定回転数に対する 流量の変化によるものではなく，回転数および流量を 固定した状態での入口案内羽根などによる予旋回の制 御によるものである ${ }^{(9)}$. 表 1 中の Rossby 数 $R_{o}$ は式(2)

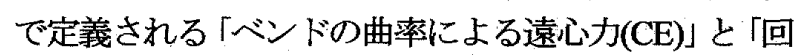
転によるコリオリ力(CO)」 の流路渦形成 の相対的な 影響の強さを表している.したがって表 1 の各条件は, 前者が支配的となる場合 $\left(R_{o}=2.08\right)$, 両者が同程度とな る場合 $\left(R_{o}=1.04\right)$ およ゙後者が支配的となる場合 $\left(R_{0}=0.69\right)$ にそれぞれ対応している.

$$
R_{o}=\frac{V_{c} / R_{c}}{\omega}=\frac{[\mathrm{CE}]}{[\mathrm{CO}]}
$$

\section{5. 計篮轺果およひ若宗}

表 1 および表 2 に示す解析条件に対する計算結果を 以下に示す. すべての解析において同一の計算格子を 用W，格子数は 125 (流路方向 $) \times 35$ (幅方向 $) \times 35$ (高さ方 向)である.

本研究では回転曲がりダクト(RCD)の他に, 同じ曲 がりダクトに対して $N=0 \mathrm{rpm}$ に設定した静止曲がりダ クト(SCD), および同じ断面形状および全長を有する 静止直線ダクト(SSD)内の流れも, 回転曲がりダクトと 同じ入口速度分布の条件を与えて解析を行った(図 5). SSD の計算格子数は曲がりダクトと同じである. 静止 場の SSD および SCD においては, 全圧損失係数 $C_{p t}$ を式(3)により定義した。

$$
C_{p t}=\frac{p_{t r e f}-p_{t}}{\rho V_{c}^{2} / 2}
$$

ここで， $p_{t}$ は全圧， $p_{\text {ref }}$ は基準全圧(ダクト入口断面質 量平均全圧)である. また，回転場の RCD に対する全 圧損失係数 $C_{p i}{ }^{*}$ は式(4)で定義した。

$$
C_{p t}^{*}=\frac{p_{t r e f}^{*}-p_{t}^{*}}{\rho V_{c}^{2} / 2}
$$




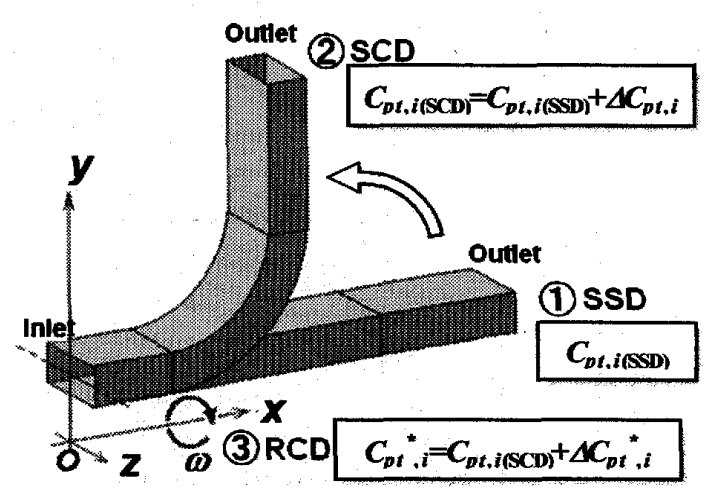

Fig.5 Definition of mass-averaged total pressure losses

ここで, $p_{t}^{*}$ 㤌回転による圧力上昇を除いた全圧である.

図 5 に示寸ように, SSD，SCD および RCD の同一 入口速度分布に対する解析結果において，ダクト入口 から同一流路方向距離における断面での断面質量平均 (7)全圧損失係数をそれぞれ， $C_{p t,(\mathrm{SSD}),}, C_{p t(\mathrm{SCD})}$ および $C_{p t, i}{ }^{*}$ とする. SSD(図 5 中(1))内では「4つの壁面上での境界 層の発達に起因する損失 $C_{p t \longleftrightarrow(\mathrm{SSD})\rfloor}$ が生じ， $\mathrm{SCD}$ (図 5 中(2))内では $C_{p t \text { (SSD) }}$ に「ベンドの曲率による遠心力(CE) に誘起される流路渦に起因する損失 $\left.\Delta C_{p(i}\right\rfloor$ が加わり $C_{p t(\mathrm{SCD})}$ の総損失が発生する: さらに RCD(図 5 中(3))内 では $C_{p t,(\mathrm{SCD})}$ に「回転によるコリオリ力(CO)の付加によ る流路渦の増強分に起因する損失 $A C_{p t, i}{ }^{*}$ が加わり $C_{p t, i}{ }^{*}$ の総損失を生じる. 本研究では以上のように定義され る各種全圧損失係数により, 各ダクト内において二次 流れを構成する流路渦に起因する損失の評価を行った。 また，二次流れの強さは， $V_{c}$ て無次元化した相対流れの 二次流㭪度成分に対する渦度の流路方向成分の絶対值 $\omega_{\text {iabs }}$ により評価した ${ }^{(7)} . \omega_{\text {iabs }}$ は $V_{c}$ て無次元化された相対 二次流れ速度成分借基づく渦度の流路方向成分の絶対值で あり，次式で定義される。

$$
\omega_{i a b s}=\left|\frac{\partial\left(w_{\zeta} / V_{c}\right)}{\partial \eta}-\frac{\partial\left(w_{\eta} / V_{c}\right)}{\partial \varsigma}\right|
$$

ここで，クとらはそれぞれ管軸方向に垂直な断面内の管 幅と管高さ方向の座標， $w_{\eta}$ と $w_{\zeta}$ はそれそれれ相対速度 の $\eta$ とら方向成分である.

5-1 觧止曲がりダクトの㘿合 図 6 に静止曲が りダクトにおける, 全圧損失倸数 $C_{p t}$ の断面質量平均 值 $C_{p t i(\mathrm{SCD})}$ の流路方向分布を, ベンド入口 $\left(X_{s}=0.0\right)$ での 值を基淮に示す. 図中の $X_{s}$ はベンドの入口 $\left(\theta=0^{\circ}\right)$ を 原点とし, ベンド部の平均曲率半径での円弧の長さ $\pi R_{c} / 2$ で無次元化した, ダクト中心軸での流路方向の 距離である. したがうて $X_{s}$ はベンド出口 $\left(\theta=90^{\circ}\right)$ で 1.0 の值をとる. 図6 の曲がりダクトの $C_{p t(\mathrm{SCD})}$ から,

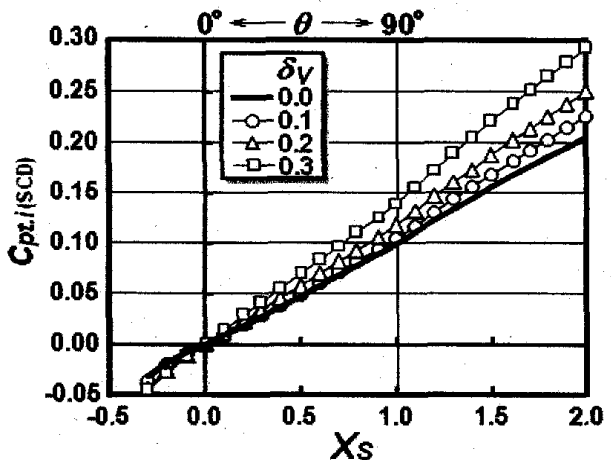

Fig.6 Total pressure loss coefficient (SCD)

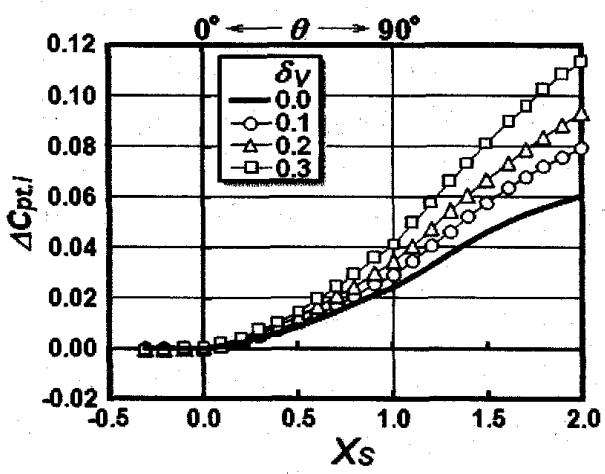

Fig.7 Total pressure loss caused by CE(SCD)

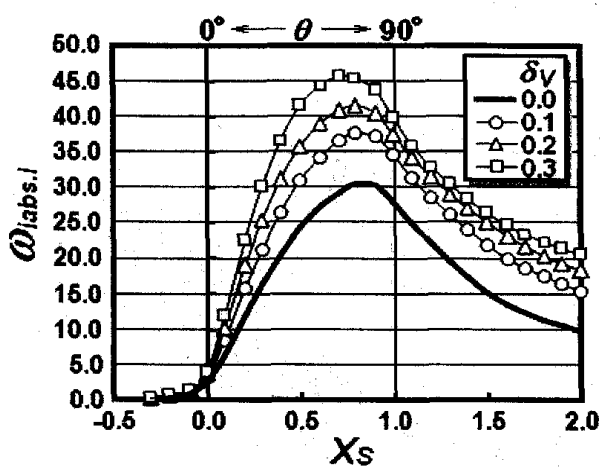

Fig.8 Streamwise component of vorticity (SCD)

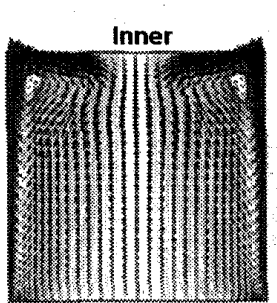

(a) $\delta_{V}=0.0$

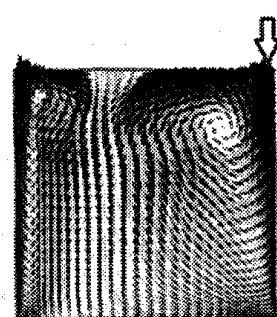

(b) $\delta_{V}=0.1$

$$
\left(\rightarrow: 0.3 V_{C}\right)
$$

Fig.9 Secondary flow velocity vectors at $\theta=90 \mathrm{deg}$. (SCD)

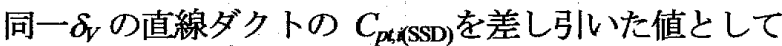
定義される $\Delta C_{p h i}$ の流路方向分布を図 7 に示寸. 図 8 に は二次流れの強さの指標となる $\omega_{\text {iabs }}$ の断面質量平均值 
$\omega_{\text {iabs,i }}$ の流路方向分布を示す. 図 9 にベンド出口 $\left(\theta=90^{\circ}\right)$ での二次流れ速度べクトルと二次流れ流線 を重ねた図を示す。

図 6 から, SCD においては $\delta_{V}$ の増加により総損失 $C_{p t,(\mathrm{SCD})}$ が増加することが分かる. また CE に誘起され る流路渦に起因する損失 $A C_{p t}$ (図 7)および二次流れの 強さを表す $\omega_{\text {iabs, }}$ (図 8)についても $\delta_{V}$ の増加にともなっ て増加している. さらに図 9 に示寸二次流れ速度べク トルから, 速度勾配を付加した側の側壁面(図 9 中矢印 側)上で内壁一向から二次流れが強くなり，それによる 同側壁側の流路渦の発達により，流路渦の対称性が崩 れることが分かる. 以上の結果から静止曲がりダクト においては，片方の側壁上の境界層厚さを他方より厚 くすることにより厚い側の流路渦が発達し，その発達 の程度は境界層厚さの増加とともに強くなる．その結 果，流路渦に起因する損失が増加するため総損失が増 加することが分かる(7).

5.2 回狋曲がりダクト $R_{0}=1.04$ の場合 $\mathrm{CE}$ と CO の流路渦形成への相対的な影響の強さが同程度となる $R_{o}=1.04$ の場合の計算結果を示す. 図 10 に全圧損失係 数 $C_{p t}{ }^{*}$ の断面質量平均值 $C_{p t, i}{ }^{*}$ の流路方向分布をべンド 入口 $\left(X_{s}=0.0\right)$ での值を基準に示す. 回転曲がりダクトの各 $\delta_{V S}$ または $\delta_{V P}$ に対する $C_{p t, i}{ }^{*}$ の分布(図 10)から，同一の値

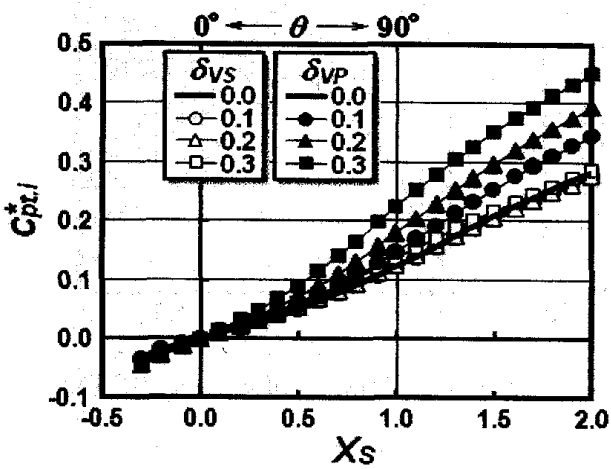

Fig.10 Total pressure loss coefficient $\left(R_{o}=1.04\right)$

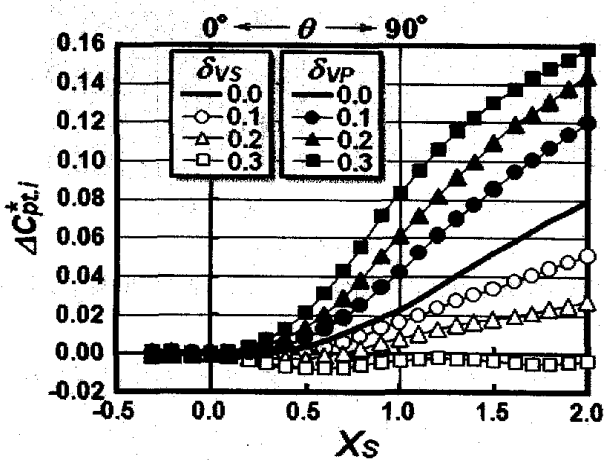

Fig.1 1 Total pressure loss caused by rotation $\left(R_{o}=1.04\right)$
の $\delta_{V}$ に対する静止曲がりダクトの $C_{p h \text { ( }(\mathrm{SCD})}$ の分布(図6)を差 し引いた值しして定義される $\Delta C_{p t, i}{ }^{*}$ の流路方向の分布を 図 11 に示寸. 図 12 には, $\omega_{\text {iabs }}$ の断面質量平均值 $\omega_{\text {iabs } i}$

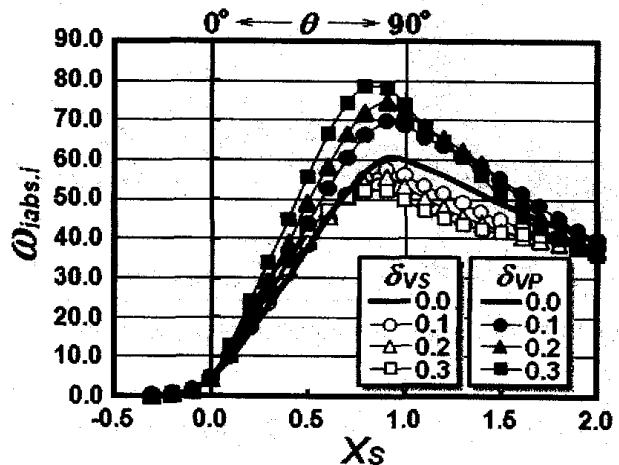

Fig.12 Streamwise component of vorticity $\left(R_{o}=1.04\right)$

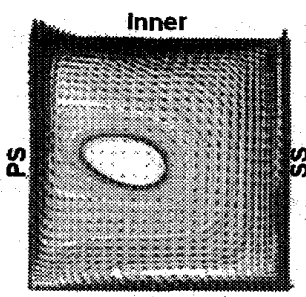

$(\theta=30 \mathrm{deg}$.

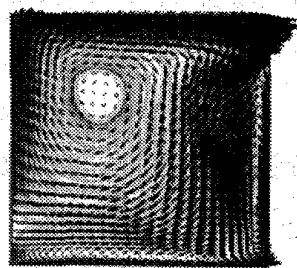

( $\theta=90 \mathrm{deg}$.) (a) $\delta_{V S}=\delta_{V P}=0.0$

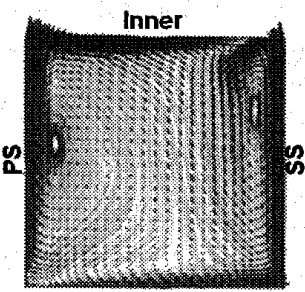

$(\theta=30 \mathrm{deg}$.)

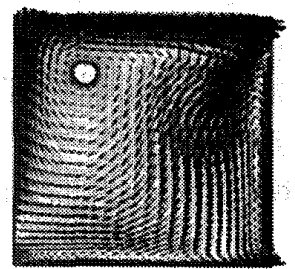

( $\theta=90 \mathrm{deg}$.) (b) $\delta_{S_{S}}=0.1$

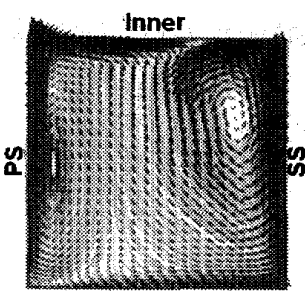

( $\theta=30 \mathrm{deg}$.)

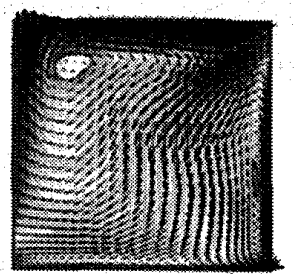

( $\theta=90 \mathrm{deg}$. (c) $\delta_{\mathrm{S}}=0.2$

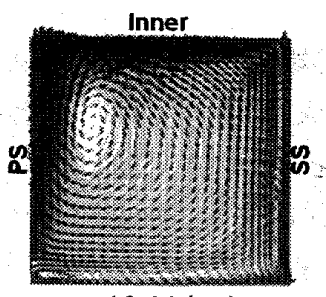

$(\theta=30 \mathrm{deg}$.)

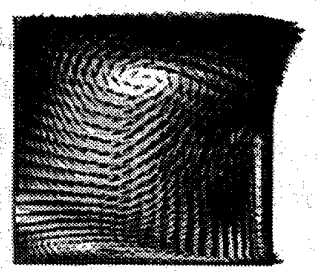

$(\theta=90 \mathrm{deg}$. (d) $\delta_{V P}=0.1$

$\left(\rightarrow: 0.3 V_{C}\right)$

Fig.13 Secondary flow velocity vectors $\left(R_{o}=1.04\right)$ 
の流路方向分布を示す. 図 13 にベンド内前半部 $\left(\theta=30^{\circ}\right)$ と出口 $\left(\theta=90^{\circ}\right)$ での二次流れ速度ベクトル と二次流れ流線を重ねた図を示す.図 14 にはベンド出

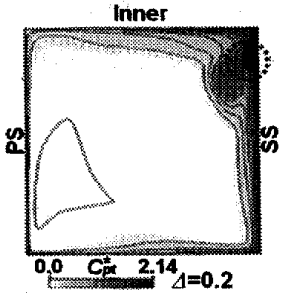

(a) $\delta_{V S}=\delta_{V P}=0.0$

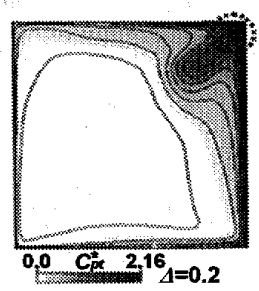

(b) $\delta_{\mathrm{V}}=0.1$

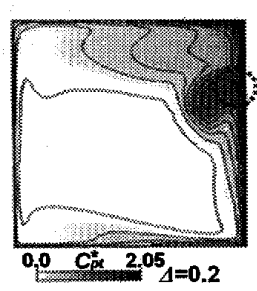

(c) $\delta_{\eta p}=0.1$
Fig.14 Total pressure loss distribution at $\theta=90 \mathrm{deg} .\left(R_{o}=1.04\right)$

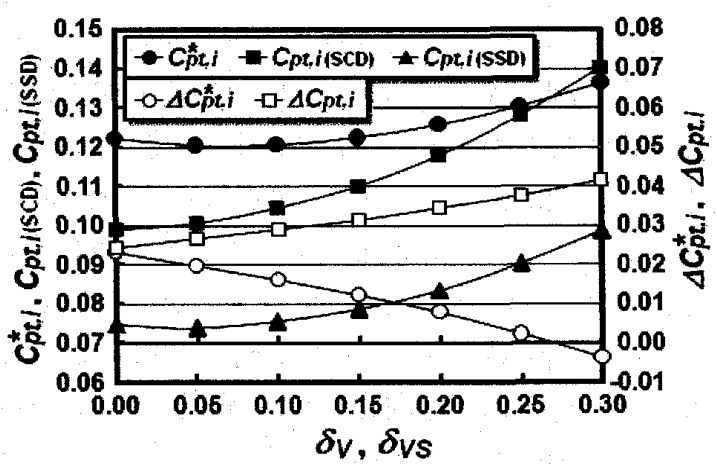

(a)Suction side

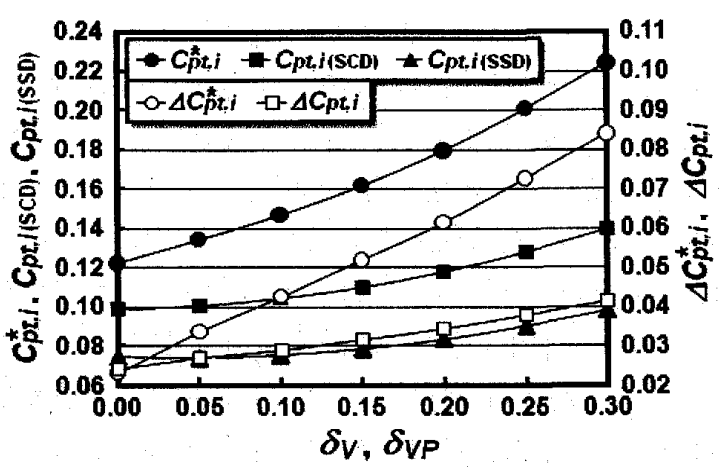

(b)Pressure side

Fig.15 Losses at $\theta=90 \mathrm{deg}$. $\left(R_{o}=1.04\right)$

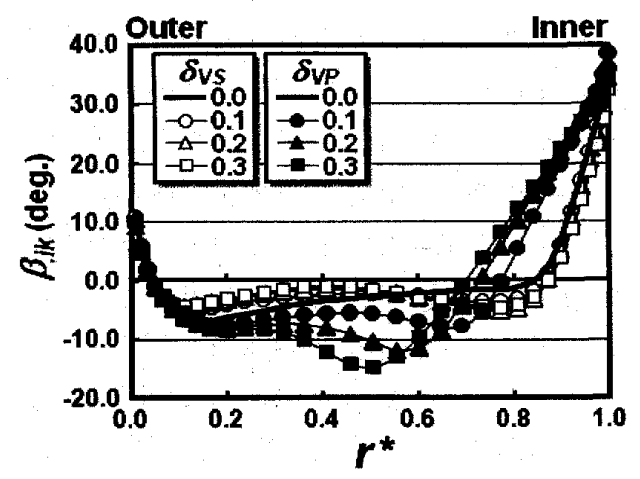

Fig.16 Deviation angle at $\theta=90 \mathrm{deg} .\left(R_{o}=1.04\right)$
口 $\left(\theta=90^{\circ}\right)$ 断面内の全圧損失係数 $C_{p t}{ }^{*}$ の分布を示す.

図 10 から $\delta_{V S}$ の増加に対しては全圧損失 $C_{p t, i}{ }^{*}$ はほと んど変化しないが， $\delta_{y p}$ の増加に対しては明確に増加す ることが分かる. 図 11 に示寸 $\Delta C_{p t, i}^{*}$ はベンド入口付近を 境に $\delta_{V S}$ の増加に対しては堿少し, 一方 $\delta_{V P}$ の増加に対し ては増加している. 同様に二次流れの強さを示す $\omega_{\text {iabs } i}$ についても $\delta_{V S}$ の増加に対しては减少し, $\delta_{V P}$ の増加に対 しては増加している(図 12). 断面内の二次流九の形成状 態に着目すると(図 9,13)，一様入口速度分布 $\left(\delta_{V}=\delta_{V S}=\right.$ $\left.\delta_{V P}=0.0\right)$ では SCD の場合は CE の影響により両側壁付 近に対称な一対の流路渦を形成するが(図 9(a)), RCD の場合は $\mathrm{CO}$ の影響が加わることにより内壁面上の境 界層内に PS から SS 向から二次流れが誘起され，そ の結果 PS の流路渦が発達する(図 13(a)). また, SCD の場合は前述のように速度勾配を付けた側壁側の流路 渦が発達する(図 9(b)). 以上の SCD および RCD 内の 流路渦の挙動を考慮すると， RCD においては $\mathrm{SS}$ 壁面 上での $\delta_{r S}$ の増加は，同壁面上を内壁へ向かう二次流れ を強め, その結果 SS の流路渦を発達させることによ り CO の作用に起因する PS の流路渦の発達を抑え， 断面内の二次流れを一様速度分布の場合よりも抑制す ることが分かる(図 13(b),13(c)). 一方 PS 壁面上での $\delta_{V P}$ の増加は, 同壁面上を内壁へ向かう二次流れを強め, その結果 PS の流路渦を発達させることにより CO の 作用に起因する PS の流路渦の発達を増進させること が分かる(図 13(d)).

以上の結果から，RCDのベンド入口 SS 壁面上の境 界層厚さの増加は SS の流路渦を発達させることによ り，CO の作用に起因する PS の流路渦の発達を抑える ため, CO の付加による流路渦の増強分に起因する損 失 $\Delta C_{p t, i}{ }^{*}$ 老低減させ, 結果として総損失 $C_{p t, i}{ }^{*}$ の増加を 抑える. 一方, 入口 PS 壁面上の境界層厚さの増加は, COの作用に起因するPS の流路渦の発達を増進させる ため $\Delta C_{p t, i}{ }^{*}$ を増加させ, 結果として総損失 $C_{p t, i}{ }^{*}$ の増加 を引き起こす. また図 13 と図 14 との比較から, 高損 失領域(図 14 中破線の円)の位置は一様流入の場合を基 淮とすると， $\delta_{V S}$ の増加はPS の流路渦を抑制するため 内壁側人，一方 $\delta_{V P}$ の増加はPS の流路渦の発達させる ため外壁側へ移動させることが分かる.

図 15 にベンド出口 $\left(\theta=90^{\circ}\right)$ での各種損失の $\delta_{r 5} お よ$ び $\delta_{V P}$ に対する変化を示す. 図 16 には図 2 で定義され ているべンド出口での流れ角 $\beta$ の管幅(j)方向に質量平 均()した值 $\beta_{i k}$ の $\boldsymbol{r}^{*}$ 方向分布を示寸。ここで $\boldsymbol{r}^{*}$ は外壁を 原点とし内壁で 1.0 となる管高さ方向無次元座標であ る. 流れ角队は遠心羽根車ではその性能を左右する羽 根車出口でのすべりに影響を与え, 圧力面側への偏向 


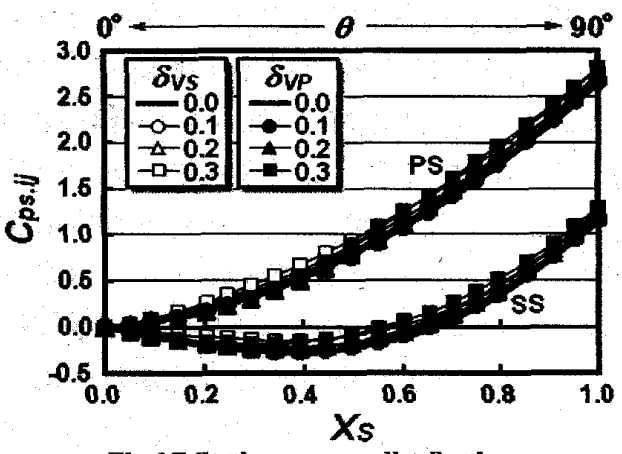

Fig.17 Static pressure distribution on side walls $\left(R_{o}=1.04\right)$

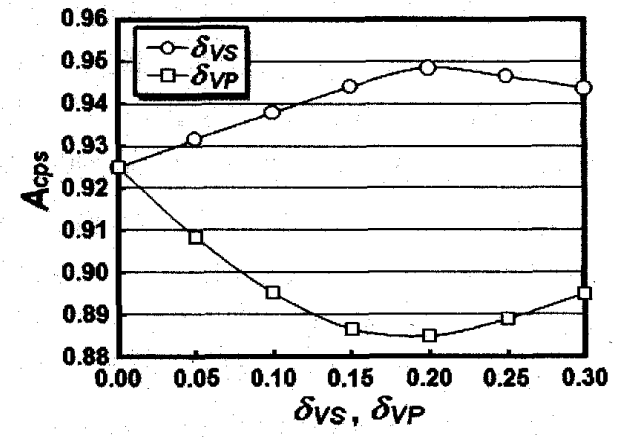

Fig. 18 Loading coefficient $\left(R_{o}=1.04\right)$

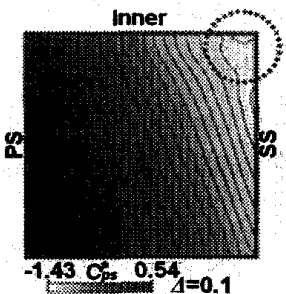

(a) $\delta_{w S}=\delta_{V P}=0.0$

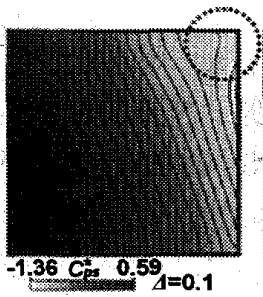

(b) $\delta_{\mathrm{is}}=0.1$

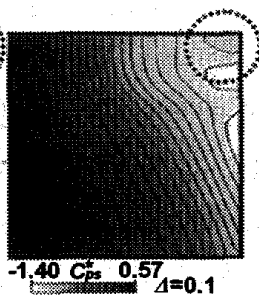

(c) $\delta_{V P}=0.1$
Fig.19 Reduced static pressure distribution at $\theta=90 \mathrm{deg} .\left(R_{o}=1.04\right)$

を示す負の值はすべりを増加させる. 図 15 から $R_{o}=1.04$ では CE とCO の流路渦形成への相対的な影響 の強さが同程度であるため，一様入口速度分布 $\left(\delta_{V P}=\delta_{V S}=0.0\right)$ の場合は $\Delta C_{p t i}$ と $\Delta C_{p t, i}{ }^{*}$ がほぼ同じになっ ていることが分かる．また， $\delta_{V P}$ の増加は RCD の総損 失 $C_{p t, i}{ }^{*}$ を構成する全ての損失を増加させている(図 15(b)). 一方 $\delta_{W s}$ の増加は CO の付加による流路渦の増 強分に起因する損失 $\Delta C_{p t, i}{ }^{*}$ を堿少させ(図 15(a)), その結 果 $\delta_{W S}=0.05 \sim 0.1$ 付近での総損失 $C_{p w i}{ }^{*}$ が一様入口速度分 布の場合 $\left(\delta_{r s}=0.0\right)$ よりも低减されている. また $\delta_{r s}=0.3$ では $\Delta C_{p t, i}{ }^{*}$ が負の値を取り, RCD の総損失 $C_{p t, i}{ }^{*}$ が $\mathrm{SCD}$ の総損失 $C_{p h(\mathrm{SCD})}$ よりも小さくなっている. ベンド出口 流れ角 $\beta_{i k}$ については(図 16), $\delta_{\text {ES }}$ の増加は一様流入の場 合の $\beta_{j k}$ の負の領域を $0^{\circ}$ に近づけ，一様性も向上させ ている. 一方 $\delta_{r p}$ の増加は $\beta_{, i k}$ の負への偏向の程度を強 め, 一様性も低下させている. これらの流出角 $\beta_{, i k}$ の $\delta_{i s}$
および $\delta_{V p}$ の変化に対する傾向は, 先に示した $\delta_{V S}$ の増 加が流路洞の発達を抑制し, $\delta_{V P}$ の增加が流路渦の発達 を増進することに起因している.

図 17 に静圧係数 $C_{p s}$ をべンド内の圧力面近傍と負压 面近傍で管高さ(k)方向(図 2)に質量平均()した静圧係 数 $C_{p s i j}$ の流路方向分布を示す. $C_{p s}$ は式(の)で定義され る.

$$
C_{p s}=\frac{p-p_{r e f}}{\rho V_{c}^{2} / 2}
$$

ここで, $p$ は静圧で, $p_{r e f}$ はベンド入口 $\left(\theta=0^{\circ}\right)$ 外壁面 上中央での静圧である. 図 17 は遠心羽根車の翼面負荷 分布に対応するものと考えられる. 図 18 には図 17 の 圧力面および負圧面近傍のそれぞれの $C_{p \mathrm{sij}}$ の分布曲線 で囲まれた面積として定義される, 負荷倸数 $A_{\text {cos }}$ の $\delta_{V S}$ および $\delta_{V P}$ に対する変化を示す. $A_{\text {qps }}$ は遠心羽根車の翼 負荷に対店するものと考えられる. 図 19 にはベンド出 口断面での, 回転による圧力上昇を除いた静圧係数 $C_{p s}{ }^{*}$ 分布を示す. $C_{p s}{ }^{*}$ は土式(6)において $p$ を，回転によ る圧力上昇分を除いた静圧 $p^{*}$ に置き換えることによっ

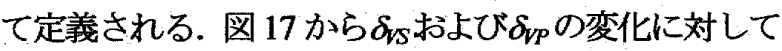
壁面近傍の $C_{\mathrm{psij}}$ の流路方向分布に顕著な変化は見られ ないが，負荷俰数 $A_{q 0}$ (図 18)は一様流入の場合に比べて速 度勾配を SS に付けると堌加し，PS に付けると低下する傾 向を示している. この傾向に対する二次流れの影響として は，図13 と図19を負圧面の内壁付近(図 19 中破線の円) に注目して比較すると，一様入口速度分布の場合 $\left(\delta_{r S}=\delta_{V P}=0.0\right)$ は PS の流路渦を構成寸る内壁面上の PS からSS 一向かう二次流れが SS 壁面へ衝突することに より，負圧面の内壁付近の静圧をわずかに上昇させて いるが, $\delta_{W S}$ の増加はその流路渦を抑制することにより 衝突による静圧上昇を抑え, 逆に $\delta_{\text {vp }}$ の増加は流路渦を 発達させることにより衝突による静圧上昇を強めると 考えられる. したがって, 流路渦の制御が負荷俰数 $A_{q q s}$ へも影響を与えることが分かる.

以上の RCD の解析結果から，遠心羽根車において も無衝突流入の設計点付近の流量において，入射角を インデューサ角度よりわずかに正へ傾け(図 3(b)), 負 圧面上の境界層厚さを圧力面側より厚くすることによ り, 羽根車流路内での二次流れの発達を抑制し, それ に起因する損失およひ羽根車出口でのすべりを低减さ せ，さらに翼面負荷を増加させることができる．逆に 入射角を負一傾け圧力面側の境界層を発達させると (図 3(c)), 二次流九の発達を増進しそれに起因する損失 およびすべりを増加させ，翼面負荷を低下させると考 えられる. 


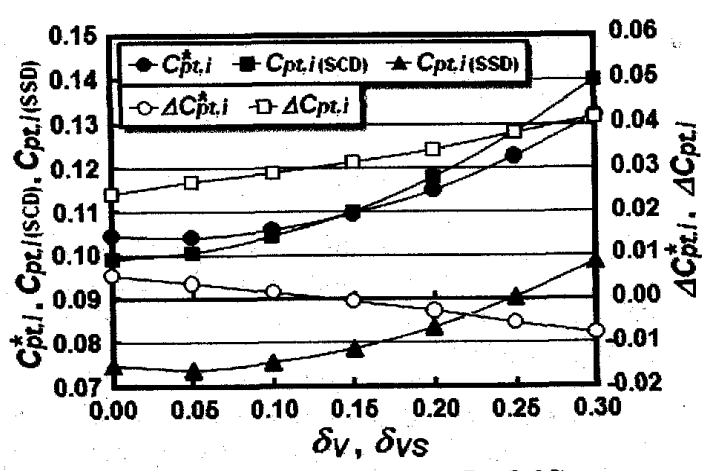

Fig.20 Losses at $\theta=90 \mathrm{deg} .\left(R_{o}=2.08\right)$

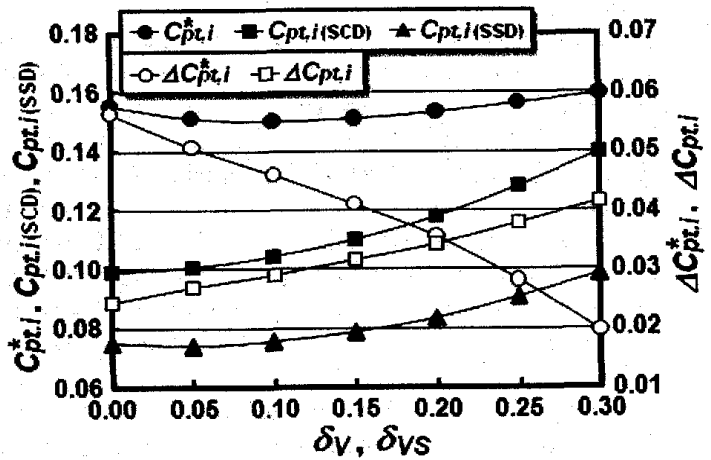

Fig.21 Losses at $\theta=90 \mathrm{deg} .\left(R_{o}=0.69\right)$

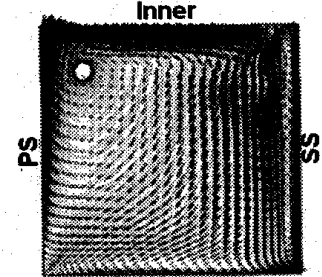

(a) $\delta_{V S}=\delta_{V P}=0.0$ $\left(\rightarrow: 0.3 V_{C}\right)$

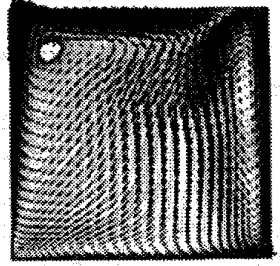

(b) $\delta_{\mathrm{S}}=0.1$
Fig.22 Secondary flow velocity vectors at $\theta=90 \mathrm{deg} .\left(R_{o}=2.08\right)$

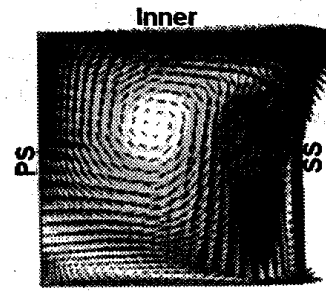

(a) $\delta_{V S}=\delta_{V P}=0.0$

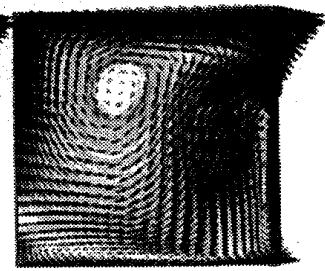

(b) $\delta_{v_{S}}=0.1$ $\left.\rightarrow: 0.3 V_{C}\right)$

Fig.23 Secondary flow velocity vectors at $\theta=90 \mathrm{deg} .\left(R_{o}=0.69\right)$

5 - 3Ro の迤いによる比较 CE と CO の流路渦形 成一の相対的な影響の程度が CE の方が強い $R_{o}=2.08(N=50 \mathrm{rpm})$ の結果と, 逆にCO の方が強い $R_{o}=0.69(N=150 \mathrm{rpm})$ の結果を, 先に示した $R_{o}=1.04$ の場 合の結果も含めて比較を行う. 図 20 と図 21 に $R_{o}=2.08$ と $R_{o}=0.69$ の場合の, ベンド出口 $\left(\theta=90^{\circ}\right)$ での各種損
失の $\delta_{\text {is }}$ にる変化をそれぞれ示す. 図 22 と図 23 には $R o=2.08$ と $R_{o}=0.69$ の場合のベンド出口 $\left(\theta=90^{\circ}\right)$ での, 二次流れ速度ベクトルと二次流れ流線を重わた図をそ れぞれ示す。

図20から $R_{o}=2.08$ ではCEの方がCOに比べて流路渦 形成への影響が相対的に強いため，一様入口速度分布 $\left(\delta_{r S}=0.0\right)$ の場合も $\Delta C_{p t i}$ が $\Delta C_{p t, i}{ }^{*}$ よりも大きくなってい る. また $R o=1.04$ の場合と同様に， $\delta_{W S}$ の増加は $\Delta C_{p t, i}{ }^{*}$ を減少させ，その結果 $\delta_{W S}=0.05$ での総損失 $C_{p t, i}^{*}$ が $\delta_{\text {S }}=0.0$ の場合よりもわずかに低減されているが, その 低減の程度は $R o=1.04$ の場合(図 15(a))よりも小さい. また, $\delta_{r s}=0.15$ 以上では $\Delta C_{p t, i}{ }^{*}$ が負の值を取り, RCD の総損失 $C_{p t, i}{ }^{*}$ が $\mathrm{SCD}$ の総損失 $C_{p t,(\mathrm{SCD})}$ より低下してい る.一方，流路渦形成一の影響が CO の方が相対的に 強い $R_{o}=0.69$ で忙(図 21), $\delta_{r S}=0.0$ の場合も $\Delta C_{p t, i}^{*}$ が $\Delta C_{p t i}$ より大きくなっている. また他の $R_{o}$ の結果と同様, $\delta_{V S}$ の増加は $\triangle C_{p i, i}{ }^{*}$ を減少させ, その結果 $\delta_{r s}=0.05 \sim 0.2$ での 総損失 $C_{p t, i}{ }^{*}$ が $\delta_{r S}=0.0$ の場合よりも低减され, その低减 の程度は $R_{o}=1.04$ の場合(図 15(a))よりも大きくなって いる. 以上の結果から, $\mathrm{CO}$ の影響の増加を示す $R_{o}$ 数 の低下により， $\delta_{r S}$ の増加にともなう $\Delta C_{p t, i}{ }^{*}$ の堿少が総 損失 $C_{p t, i}^{*}$ を $\delta_{w S}=0.0$ の場合より低减させる程度は大き くなり,さらに $C_{p t, i}{ }^{*}$ が最小值を取る $\delta_{S S}$ の值は増加する ことが分かる.この原因はつぎのとおりである. CO の影響が弱い $R_{o}=2.08$ では, PS の流路渦のCO の影響 による発達が $\delta_{W S}=0.0$ の場合もあまり強くないため, SS 壁面側一の速度勾配の付加による PS の流路渦の抑制 効果は小さい(図 22). 一方 $\mathrm{CO}$ の影響が強い $R_{o}=0.69$ では, PS の流路渦の CO の影響による発達が $\delta_{\text {以 }}=0.0$ の場合も非常に強いため, SS 壁面上への速度勾配の付 加によるその抑制効果は大きく(図 23)，また最大限に 抑制できる SS の流路渦を生み出す境界層厚さも厚く なるためである.

以上の回転曲がりダクトに対する結果から， $R_{o}$ の低 い高回転の遠心羽根車ほど，無衝突流入の設計点付近 の流量において，負圧面上の境界層厚さを圧力面側よ り厚くすることによる二次流れの発達の抑制効果，お よびそれに起因する損失生成の低減効果は大きくなる と考えられる.

\section{6. 結}

本研究において回転曲がりダクト内の流れを解 析することにより, 以下の結論を得た.

(1) ベンド入口負圧面上の境界層厚さの増加は, 負圧 面側の流路渦を発達させることにより，コリオリカの 作用に起因する圧力面側の流路渦の発達を抑えるため, 
流路渦に起因する損失を低減させ, その結果総損失の 増加を抑える。

(2) ベンド入口圧力面上の境界層厚さの増加はコリオ リ力の作用に起因寸る圧力面側の流路渦の発達を増進 させるため，流路渦に起因する損失を増加させ，その 結果総損失の増加を引き起こす。

(3) ベンド入口での負圧面上の境界層厚さの増加によ る流路渦の発達の抑制は，ベンド出口での流れ角を $0^{\circ}$ 八近つけると同時にその一様性を向上させ，一方 圧力面上の境界層厚さの増加による流路渦の発達の増 進は，流れ角の負への偏向の程度を強めその一様性を 低下させる.

(4) ベンド入口負圧面上の境界層厚さの増加による流 路渦の発達の抑制は，両側壁面間の圧力差を増加させ， 一方圧力面上の境界層厚さの増加による流路渦の発達 の増進は，その圧力差を低下させる.

(5) $R_{o}$ 数の低下により, ベンド入口負圧面上の境界層厚 さの増加にともなう流路渦に起因寸る損失の減少が, 総損失を一様速度分布の場合より低減させる程度は大 きくなり，さらに総損失が最大の低減量を示す境界層 厚さは增加する。

(6) 遠心羽根車の無衝突流入の設計点付近の流量にお いて、インデューサへの入射角をわずかに正八傾けて 負圧面上の境界層厚さを圧力面側より厚くすることに より，翼間内での二次流れの発達を抑制しそれに起因 する損失およひ羽根車出口でのすべりを低減させ，さ らに翼面負荷を増加できる。

(7) 遠心羽根車の無衝突流入の設計点付近の流量にお いて, インデューサへの入射角を負へ傾けて圧力面側 の境界層を発達させると，二次流れが増強しそれに起 因する損失およひ羽根車出口でのすべりが増加し，さ らに翼面負荷も低下する.

(8) Rossby 数の低い高回転の遠心羽根車ほど，無衝突 流入の設計点付近の流量において, 負圧面上の境界層 厚さを圧力面側より厚くすることによる二次流九の発
達の抑制効果，およびそれに起因する損失生成の低減 効果は大きい。

\section{文荕}

(1) Krain, H., Review of Centrifugal Compressor's Application and Development, Transactions of the ASME, Journal of Turbomachinery, Vol.127, No.1 (2005), pp.25-34.

(2) Tsujita, H. and Mizuki, S., Investigation for Secondary Flow and Loss Generation Mechanisms within Centrifugal Impeller by Using Rotating Curved Duct (1st Report, Influence of Rossby Number), Transactions of the Japan Society of Mechanical Engineers, Series B, Vol.74, No.737 (2008), pp. 111-120.

(3) Johnson, M.W. and Moore, J., Secondary Flow Mixing Losses in a Centrifugal Impeller, Transactions of the ASME, Journal of Engineering for Power, Vol.105, No.1 (1983), pp. 24-32.

(4) Tsujita, H. and Mizuki, S., Numerical Calculation of Incompressible Viscous Flow Within Curved Duct using Momentum Equations in Physical Component Tensor Form for Boundary-Fitted Coordinate System, Transactions of the Japan Society of Mechanical Engineers, Series B, Vol.57, No.540 (1991), pp. 2606-2613.

(5) Tsujita, H., Ejiri, E. and Mizuki, S., Analysis of Flow within Pump Impeller of Torque Converter, Transactions of the Japan Society of Mechanical Engineers, Series B, Vol.59, No.564 (1993), pp. 2500-2508.

(6) Tsujita, H. and Mizuki, S., Numerical Analysis of Compressible Flow Using Pressure-Correction Method, Transactions of the Japan Society of Mechanical Engineers, Series B, Vol.63, No.608 (1997), pp. 1270-1278.

(7) Tsujita, H., Ishida, Y., Mizuki, S. and Yamamoto, A., Investigation for Loss Generation Mechanisms of Flow in Turbomachinery by Using Curved Square Duct (1st Report, Influence of Inlet Velocity Distribution), Transactions of the Japan Society of Mechanical Engineers, Series B, Vol.69, No.683 (2003), pp. 1628-1636.

(8) Johnson, M.W., Secondary Flow in Rotating Bends, Transactions of the ASME, Journal of Engineering for Power, Vol.100, No.10 (1978), pp. 553-560.

(9) Kassens, I. and Rautenberg, M., Flow Measurements behind the Inlet Guide Vane of a Centrifugal Compressor, ASME Paper 98-GT-86(1998). 